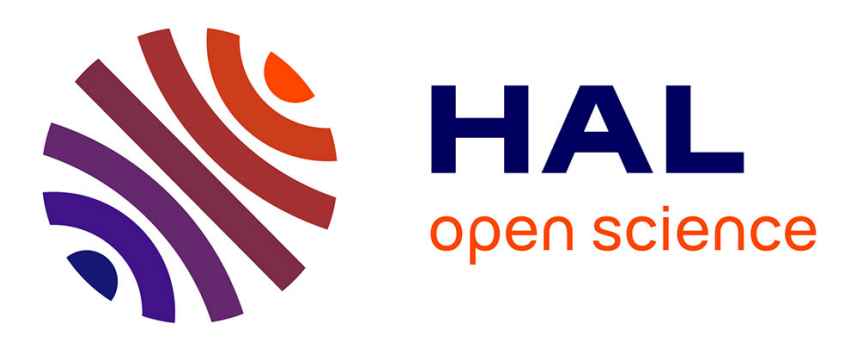

\title{
Electrical conductivity and temperature of the Earth's mantle inferred from Bayesian inversion of Swarm vector magnetic data
}

\author{
Olivier Verhoeven, Erwan Thébault, Diana Saturnino, Aymeric Houliez, \\ Benoit Langlais
}

\section{To cite this version:}

Olivier Verhoeven, Erwan Thébault, Diana Saturnino, Aymeric Houliez, Benoit Langlais. Electrical conductivity and temperature of the Earth's mantle inferred from Bayesian inversion of Swarm vector magnetic data. Physics of the Earth and Planetary Interiors, 2021, 314, pp.106702. 10.1016/j.pepi.2021.106702 . hal-03284491

\section{HAL Id: hal-03284491 \\ https://hal.science/hal-03284491}

Submitted on 19 Jul 2021

HAL is a multi-disciplinary open access archive for the deposit and dissemination of scientific research documents, whether they are published or not. The documents may come from teaching and research institutions in France or abroad, or from public or private research centers.
L'archive ouverte pluridisciplinaire HAL, est destinée au dépôt et à la diffusion de documents scientifiques de niveau recherche, publiés ou non, émanant des établissements d'enseignement et de recherche français ou étrangers, des laboratoires publics ou privés. 


\title{
Electrical conductivity and temperature of the Earth's mantle inferred from Bayesian inversion of Swarm vector magnetic data
}

\author{
Olivier Verhoeven ${ }^{\mathrm{a}, *}$, Erwan Thébault ${ }^{\mathrm{b}}$, Diana Saturnino ${ }^{\mathrm{a}}$, Aymeric Houliez ${ }^{\mathrm{c}}$, Benoit Langlais ${ }^{\mathrm{a}}$ \\ a Laboratoire de Planétologie et Géodynamique, Université de Nantes, Université d'Angers, CNRS, UMR 6112, Nantes, France \\ ${ }^{\mathrm{b}}$ Laboratoire Magma et Volcan UMR 6524, Campus des Cézeaux, Avenue Blaise Pascal, 63130 Aubière, France \\ ${ }^{\mathrm{c}}$ Royal Observatory of Belgium, 3, Avenue Circulaire, 1180 Brussels, Belgium
}

\section{A R T I C L E I N F O}

\section{Keywords:}

Swarm

Electrical conductivity

Mantle temperature

2020 MSC: 00-01, 99-00

\begin{abstract}
A B S T R A C T
Study of induced magnetic field is a powerful way to sound Earth internal structure. This work presents a full analysis and interpretation in terms of electrical conductivity and temperature of vector magnetic field measurements from Swarm Level1b data product from 26/11/2013 to 31/12/2019. Time series of the Gauss coefficients associated with the induced and inducing magnetic field are obtained from the data after removal of the core and lithospheric fields models and data selection. A Bayesian inversion of the induced field Gauss coefficients is then performed to obtain a new estimate of Earth's 1D mantle electrical conductivity down to 2000 $\mathrm{km}$ depth. This profile is fully compatible with the profiles derived from satellite and ground magnetic observatories data but does not present in the lower mantle the increase predicted by laboratory-based conductivity profile associated to classical mantle composition and temperature profile. Using the most recent database to model the electrical conductivity of all mineral mantle phases, two different methods are used to interpret $S w a r m$ data in terms of temperature for a given composition and water content. The first one is based on an interpretation of the conductivity estimates in terms of temperature by classical numerical root search. The second one consists in inferring a temperature probability density function from a Bayesian inversion of the Gauss coefficients associated to the induced magnetic field. Our results show that the later provide more reliable estimates of mantle temperatures, in relation to more physically grounded prior values. This second method provides also tighter constraints on the electrical conductivity estimates of the lower mantle.
\end{abstract}

\section{Introduction}

Electromagnetic sounding offers an opportunity to obtain information on temperature and composition of the Earth's mantle. Indeed time varying external magnetic field induces electrical currents in the conducting mantle that will generate in response an induced magnetic field. Such currents are governed by the electrical conductivity of the mantle, which depends mainly of pressure, temperature and composition, including the water content (e.g. Yoshino, 2010).

Solving the global induction problem consists in computing the radial electrical conductivity distribution from time series of magnetic field measurements recorded outside the conductive mantle, either at ground magnetic observatories or by Low Earth Orbiting satellites measuring the Earth's magnetic field (see e.g. the reviews of Le Mouël (1976) or Constable (2015)). Once some selection is applied to the data and the contributions of the core and lithosphere are removed, these measurements are still the sum of the inducing and induced contributions and the computation of the electrical conductivity needs therefore a careful separation between these two parts. As the penetration depth of the signal increases with its period, the identification of periodic variations in the magnetic field allow to sound the electrical conductivity of the mantle at different depths. The linearity of the Maxwell equations with respect to the sources allows moreover to select the most dominant harmonics in the external magnetic field. Following the pioneer study of Banks (1969), most of global induction studies focus on the first zonal harmonic $P_{1}^{0}$ in relation to the geometry of the ring current.

Solving the global induction problem is usually achieved in two steps: the first one consists in computing, from magnetic measurements, the frequency dependent response function, which is classically expressed as impedances, C or Q-functions (e.g. Olsen, 1999a). The second one is devoted to the computation of the electrical conductivity governing the response function. If we focus on radial conductivity

\footnotetext{
* Corresponding author.

E-mail address: Olivier.Verhoeven@univ-nantes.fr (O. Verhoeven).
} 
profile represented by piece-wise constant function, the second step consists in solving the Maxwell equations in a multi-layered spherically symmetrical Earth according to the transfer matrix formalism developed by Srivastava (1966). An additional step is required to interpret the electrical conductivity in terms of temperature and composition. This last step is achieved through the comparison between the computed conductivity profile and the latest laboratory measurements of the minerals conductivity performed at high pressure and high temperature conditions (see e.g. Constable (2015)). In this paper, we propose to organize the two later steps in a single inversion scheme and interpret the Q-response function directly in terms of temperature, associated with a given composition. This strategy allows us to avoid using a priori knowledge on the conductivity and to rely instead on physicallygrounded a priori knowledge on temperature. Such scheme was already used by Khan et al. (2006) to obtain some information on composition and thermal state of the mantle from inversion of longperiod electromagnetic sounding data from European observatories.

Mantle conductivity profiles have been estimated from magnetic fields measurements since the pioneer works of Lahiri and Price (1939), McDonald (1957) and Banks (1969). Such early estimates have been improved with the growing number of magnetic data available in both space and time. For example, Olsen (1999b) used time series of daily mean values recorded at 42 European observatories during 50 years to estimate C-responses for periods between 30 days and 1 year, allowing to sound the mantle until $1800 \mathrm{~km}$ depth. With the uniform sampling of the entire Earth, satellites have considerably extended the coverage beyond the continental measurements performed at ground magnetic observatories, although their movement around the Earth complicates the identification of the temporal variations (Olsen, 1999a). Over the past two decades, many induction studies were carried out from space, providing global estimates of the electrical conductivity profile of the Earth's mantle (e.g. Constable and Constable (2004), Kuvshinov and Olsen (2006), Velímský (2010), Civet and Tarits (2013), Grayver et al. (2017), Grandis and Tarits (2019)). The latest three satellite Swarm mission is the most suitably designed to study induced magnetic field as its simultaneous measurements of the magnetic field at different locations and local times permit a robust separation of the internal and external magnetic field contributions, leading to new information on the radial electrical conductivity structure of the Earth's mantle (Püthe and Kuvshinov, 2013; Civet et al., 2015; Püthe et al., 2015).

During the same decades, experimental developments and progress have allowed to reproduce in laboratory pressure and temperature conditions relevant to Earth's mantle, and reliable measurements of the conductivity of minerals have been obtained (see e.g. the reviews of Yoshino (2010), Karato (2011), Khan (2016) and Fullea (2017)). Such measurements allow to identify, for each mineral phase, the sensitivity of the conductivity to temperature along with the chemistry of the mineral phase such as iron content, partial melt and water, allowing the interpretation of electrical conductivity in terms of internal structure. These results have recently been used by Grayver et al. (2017) to evaluate the water content of the upper mantle and transition zone from a joint inversion of satellite-detected tidal and magnetospheric signals and by Munch et al. (2018) and Munch et al. (2020) to infer the water content and thermal structure of the upper mantle and transition zone from geomagnetic observatory data. In combination with seismological models, the electrical conductivity can also be used to investigate the 3D thermo-chemical structure of the Earth's lower mantle (Deschamps (2015) and Deschamps and Khan (2016)).

Study of the thermal state of the Earth's mantle is a very important subject in geophysics and geology as this state drives the whole dynamics of the Earth. The computation of the mantle temperature cannot however be measured directly and classical temperature profiles use radioactive heat generation and heat transfer modelling to interpolate anchor points derived from the laboratory measurements of Clapeyron slopes of the olivine transitions associated to seismic discontinuities at 410 and $660 \mathrm{~km}$ depth (see e.g. Katsura et al. (2004), Stacey and Davis
(2008), Jaupart et al. (2015)). The reliability of high pressure and high temperature measurements of mineral physics data such as elastic properties or electrical conductivity has largerly increased for the last twenty years and offers now a real opportunity to provide additional and independent constraints on mantle temperature from an inversion of geophysical data such as seismic, geodetic or electromagnetic data. Following the pioneer work of Birch (1952), many recent studies (e.g. Jackson (1998), da Silva et al. (2000), Marton and Cohen (2002), Deschamps and Trampert (2004), Cammarano et al. (2005), Mattern et al. (2005), Khan et al. (2006), Matas et al. (2007), Khan et al. (2008), Xu et al. (2008),Cobden et al. (2009), Murakami et al. (2012), Zhang et al. (2013), Wolf et al. (2015), Wu (2016)), focusing on different data and using different methods and/or mineralogical models have led to different results about temperature and composition of the Earth's mantle, although a pyrolite composition and a superadiabatic thermal profile in the lower mantle seem favored. The difficulty is to decorrelate temperature from composition effects and a joint inversion of the whole data set is the most relevant way to overcome this limitation (see e.g. Verhoeven et al. (2009)).

The paper is organized as follows: Section 2 describes the data processing along with the method used to identify the induced and inducing components in the Swarm measurements and their relation to electrical conductivity. The database used to model the electrical conductivity of mineral phases is discussed in Section 3, along with the modelling of electrical conductivity from temperature and composition. Section 4 is devoted to the description of the Bayesian inversion scheme of Swarm data used to obtain information on electrical conductivity and temperature. The results of this inversion are presented and discussed in Section 5 .

\section{Geomagnetic data}

\subsection{Data selection and residuals computation}

We use vector magnetic field measurements from Swarm Level1b data product, version 0505 (0506 for some data files). All three Swarm satellites are considered covering the period from 26/11/2013 to 31/ $12 / 2019$. Data is screened for quality flags defined in the Level $1 \mathrm{~b}$ Product Definition Document (Tøffner-Clausen and Nielsen, 2018). We keep only measurements identified as being in nominal mode (also Swarm C vector measurements after 4/11/2014). We use only night time data from $7 \mathrm{pm}$ to $5 \mathrm{am}$ local time and whose magnetic latitude is below $55^{\circ}$ degrees. Additionally, we select only data where the sun is at least $5^{\circ}$ below the horizon. Regarding magnetic activity level, data is chosen when $K p \leq 4^{-} ;|D s t| \leq 100 \mathrm{nT}$; interplanetary magnetic field components $B_{y}$ and $B_{z} \leq 40 \mathrm{nT}$; and finally when index F10.7 $\leq 10^{3} 10^{22} \mathrm{Wm}^{-2} \mathrm{~Hz}^{-1}$. This data selection excludes very active periods corresponding to magnetic storms. Due to their dynamic and transient nature, such extreme events are indeed not convenient for global field modelling as they require large spherical harmonics expansion as well as rapid time parameterization.

Solving the global induction problem requires the contributions from external magnetic field and induced counterparts to be isolated from other fields such as the core and the lithospheric fields. This procedure known to be challenging requires using models derived with the same instruments in order to minimize bias and artefacts (Finlay et al., 2017). The selected measurements $\left(\mathbf{B}_{\text {sel }}\right)$ are corrected from a core $\left(\mathbf{B}_{c}\right)$ and a lithospheric $\left(\mathbf{B}_{l}\right)$ field models, using Swarm L2 products model files. For the core field we use, up to SH degree $n=16$, the Comprehensive model updated from Sabaka et al. (2018), using the file $S W_{-} O$ PER_MCO_SHA_2C_20131125T000000_20200401T000000_0601. shc. This model is obtained as a comprehensive co-estimation of the core, lithosphere, ionosphere, and magnetosphere field contributions including induced contributions. For the lithospheric field, we use a model relying on successive magnetic field regional analyses from space (Thébault, 2006) following a protocol developed in the framework of the 


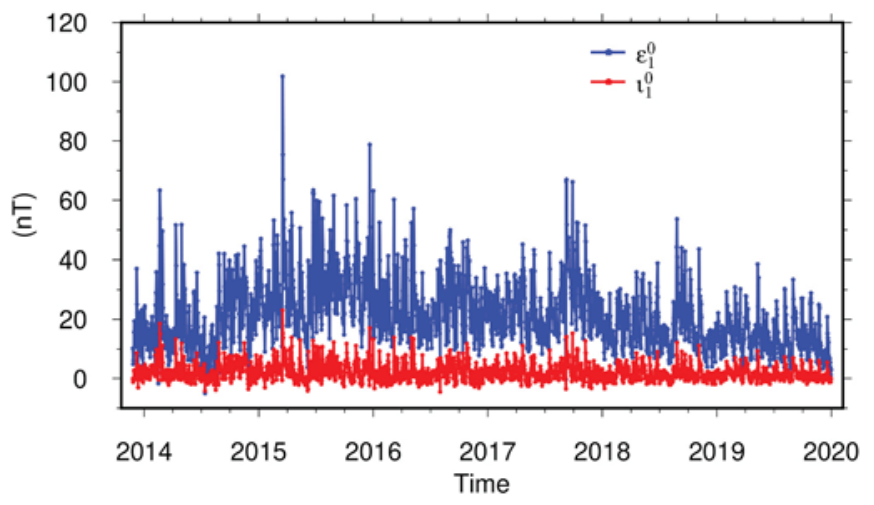

Fig. 1. Magnitude of the time series of the internal $\iota_{1}^{0}$ (in red) and external $\varepsilon_{1}^{0}$ (in blue) Gauss coefficients estimated day by day over a period of 2227 days from the Swarm A, B and C measurements between November 26th 2013 and December 31st 2019. The large amplitude event during mid March 2015 is named "St Patrick's day" storm (e.g. Astafyeva et al., 2015). (For interpretation of the references to colour in this figure legend, the reader is referred to the web version of this article.)

Swarm mission (Thébault et al., 2016). Finally, the obtained residuals $\left(\mathbf{B}_{\text {res }}=\mathbf{B}_{\text {sel }}-\mathbf{B}_{c}-\mathbf{B}_{l}\right)$ are visually inspected and a few tracks (mostly for Swarm A) are identified as obvious outliers and are removed. A final statistical filter was applied to the three satellites and the three magnetic components data to reject measurements that differ by more than 5 times the standard deviation around the mean residual value. The obtained residuals are assumed to characterize the time-varying inducing and induced magnetic fields.

\subsection{Magnetospheric potential}

For low-orbit satellites flying in a source-free region, the magnetic field $\mathbf{B}$ is derived from a scalar magnetic potential, $V$, as $\mathbf{B}=-\nabla V$ and the potential obeys Laplace's equation, $\nabla^{2} V=0$. The selected measurements were then represented in terms of internal and external spherical harmonics (SH) up to SH degree 1 in the geocentric reference frame and time scale on a daily basis in order to reduce the effect of the ionospheric field prominent at shorter periods. For periods longer than 1 day, the major source of the external field is assumed to be the ring current in the Earth's magnetosphere, which translates into a geometry where the source is dominated by spherical degree $n=1$ and order $m=$ 0 . Under these approximations, the magnetospheric potential can be written in the frequency domain as

$V(\boldsymbol{r}, \omega)=a\left[\varepsilon_{1}^{0}(\omega)\left(\frac{r}{a}\right)+l_{1}^{0}(\omega)\left(\frac{a}{r}\right)^{2}\right] P_{1}^{0}(\cos \theta)$

where $a=6371 \mathrm{~km}$ is the mean Earth's radius, $\omega$ is the angular frequency $\omega=\frac{2 \pi}{T}$, with $T$ as the period, and $\mathbf{r}=(r, \theta, \phi)$ is the position vector in the geocentric reference frame with, respectively, the distance from the Earth's center, the co-latitude and the longitude. The complex coefficients $\varepsilon_{1}^{0}$ and $l_{1}^{0}$ are the Gauss coefficients of the external (inducing) and internal (induced) parts of the potential in the Fourier domain, and $P_{1}^{0}(\cos \theta)$ is the Schmidt-normalised associated Legendre function of degree 1 and order 0 .

\subsection{Time series analysis}

By interpolating the 47 days that did not pass the selection procedure, the combined use of the three Swarm satellites allows obtaining a continuous time series for the internal and external dipole zonal coefficients over 2227 days without gap (Fig. 1).

Over the entire time period, the internal and external coefficients correlate at more than $87 \%$. However, we notice that the external co-

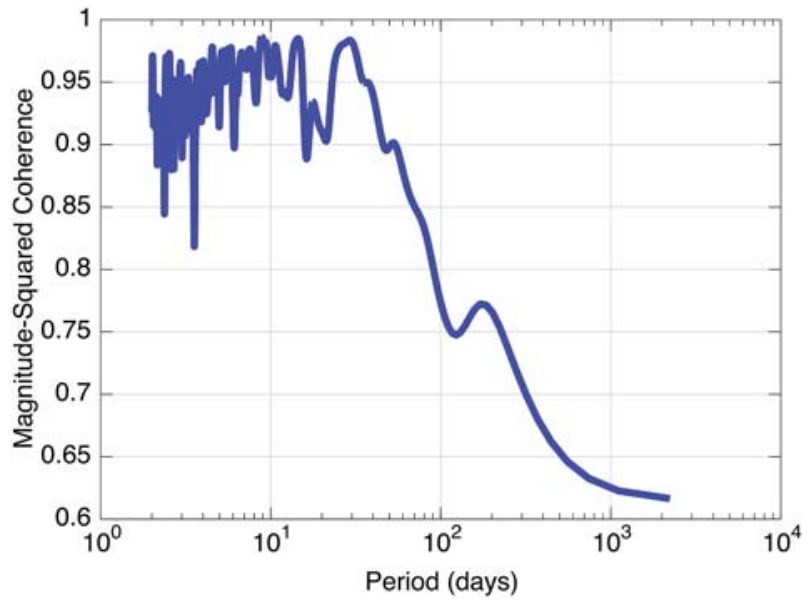

Fig. 2. Coherence analysis of the internal and external Gauss coefficients in the Fourier domain as a function of the period.

efficients possess signals at long time periods not present in the internal field ones. An analysis in the spectral domain is carried out to estimate the squared coherency between both signals as a function of the period confirms this visual inspection (Fig. 2). As can be seen, both series of coefficients correlate well for periods shorter than about 100 days. This indicates that the internal/external field separation was successfully carried out for these periods. Unfortunately, the coherence drops for periods larger than 100 days. This illustrates a fundamental problem of source field separation for long periods that could not be addressed. The major reason is that the core field model used in this study is parameterized in time using a basis of B-splines spaced about 3 months apart. As a result, the long term variations of the internal induced field is masked by the core field secular variation and their contributions are probably contained in the secular variation coefficients of the core field model (alternatively, these variations are a source of error for the secular variation model). This has an effect on the resolution of the model with depth as the penetration depth $\delta$ is a function of the time period of the signal in such a way that

$\delta \approx \sqrt{\frac{T}{\pi \mu_{0} \sigma}}$

where $\mathrm{T}$ is the period, $\mu_{0}$ the permeability of free space and $\sigma$ the electrical conductivity of the Earth's mantle. A rough calculation considering electrical conductivity values between $1 \mathrm{~S} / \mathrm{m}$ and $10 \mathrm{~S} / \mathrm{m}$ indicates that the obtained time series can probe efficiently the electrical mantle down to $1500 \mathrm{~km}$ but that the signal may be too weak or distorted to obtain a robust model for deeper layers. However, we stress that a 2227 days time series allow us to derive coefficients in the spectral domain for the short periods with reduced uncertainties compared to coefficients obtained with shorter time series (e.g. Civet et al., 2015). This should translate into more robust profiles and reduced uncertainties in the 0 $1500 \mathrm{~km}$ depth range.

\subsection{Q-response and radial electrical conductivity}

Once internal and external potentials are known for several frequencies, a model in depth of the electrical conductivity can be constructed (e.g. Le Mouël, 1976). As it is classically done, response functions are estimated from the Gauss coefficients in frequency domain, such as the Q-response, given as $l_{1}^{0}(\omega)=Q_{1}(\omega) \varepsilon_{1}^{0}(\omega)$. These functions depend on the electrical conductivity distribution inside the Earth. For a spherically symmetric Earth, the electrical conductivity is a purely radial function, i.e., $\sigma(r)$ which takes constant values on the different layers used to model the mantle. As the penetration depth (2) of 
Table 1

$\sigma_{0}^{i}, h, p, \Delta E_{i, h}, \Delta H_{p}, \Delta V_{i, h}, \alpha_{h, p}, \beta_{h}$ and $r_{p}$ coefficient values used in this study. $\sigma_{0}^{i, h, p}, \Delta E_{i, h}$ and $\Delta H_{p}$ are the pre-exponential factor, activation energy for ionic or small polaron conduction, and activation enthalpy for proton conduction, respectively. $\alpha_{h, p}, \beta_{h}$ and $r_{p}$ are coefficients governing the effect of iron and water content on small polaron and proton conduction. $\Delta V_{i, h}$ are activation volumes for ionic and small polaron conduction, respectively.

\begin{tabular}{|c|c|c|c|c|c|c|c|c|c|c|c|c|}
\hline \multirow[t]{3}{*}{ Mineral name } & \multicolumn{3}{|c|}{ Ionic conduction } & \multicolumn{5}{|c|}{ Small polaron conduction } & \multicolumn{4}{|c|}{ Proton conduction } \\
\hline & $\sigma_{0}^{i}$ & $\Delta E_{i}$ & $\Delta V_{i}$ & $\sigma_{0}^{h}$ & $\Delta E_{h}$ & $\Delta V_{h}$ & $\alpha_{h}$ & $\beta_{h}$ & $\sigma_{0}^{p}$ & $\Delta H_{p}$ & $r_{p}$ & $\alpha_{p}$ \\
\hline & $(\mathrm{S} / \mathrm{m})$ & $(\mathrm{eV})$ & $\left(\mathrm{cm}^{3} / \mathrm{mol}\right)$ & $(\mathrm{S} / \mathrm{m})$ & $(\mathrm{eV})$ & $\left(\mathrm{cm}^{3} / \mathrm{mol}\right)$ & $(\mathrm{eV})$ & $\left(\mathrm{cm}^{3} / \mathrm{mol}\right)$ & $(\mathrm{S} / \mathrm{m})$ & $(\mathrm{eV})$ & & $(\mathrm{eV})$ \\
\hline Olivine & $10^{4.73 a}$ & $2.31^{\mathrm{a}}$ & - & $525^{\mathrm{b}}$ & $1.96^{\mathrm{b}}$ & $-0.01^{\mathrm{b}}$ & $1.49^{\mathrm{b}}$ & $0.22^{\mathrm{b}}$ & $10^{1.9 a}$ & $0.92^{\mathrm{a}}$ & $1^{\mathrm{a}}$ & $0.16^{\mathrm{a}}$ \\
\hline Wadsleyite & - & - & - & $288^{c}$ & $1.45^{\mathrm{c}}$ & - & - & - & $25^{c}$ & $0.83^{c}$ & $1^{\mathrm{c}}$ & $0.2^{c}$ \\
\hline Ringwoodite & - & - & - & $1885^{\mathrm{b}}$ & $1.93^{\mathrm{b}}$ & $-0.33^{\mathrm{b}}$ & $1.46^{\mathrm{b}}$ & $0.72^{\mathrm{b}}$ & $27.7^{\mathrm{d}}$ & $1.12^{\mathrm{d}}$ & $1^{\mathrm{d}}$ & $0.67^{\mathrm{d}}$ \\
\hline Orthopyroxene & $855,610^{\mathrm{e}}$ & $2.51^{\mathrm{e}}$ & $4.15^{\mathrm{e}}$ & $163^{\mathrm{e}}$ & $2.33^{\mathrm{e}}$ & $1.06^{\mathrm{e}}$ & $1.99^{\mathrm{e}}$ & $0.12^{\mathrm{e}}$ & $10^{2.58 f}$ & $0.84^{\mathrm{f}}$ & $1^{\mathrm{f}}$ & $0.08^{\mathrm{f}}$ \\
\hline Ca-pyroxene & - & - & - & - & - & - & - & - & $10^{3.52 g}$ & $1.29^{g}$ & $0.79^{g}$ & - \\
\hline Garnet & - & - & - & $54 / 1070 / 17560^{\mathrm{h}}$ & $1.27 / 1.59 / 2.02^{\mathrm{h}}$ & - & - & - & - & - & - & - \\
\hline Bridgmanite & - & - & - & $10^{1.85 i}$ & $0.57^{\mathrm{i}}$ & $-0.3^{\mathrm{i}}$ & - & - & - & - & - & - \\
\hline Ferropericlase & _- & _- & - & $19^{j}$ & $0.63^{j}$ & $-0.45^{j}$ & $0.66^{\mathrm{j}}$ & $-0.61^{j}$ & _- & _- & _- & _- \\
\hline Akimotoite & - & - & - & $15^{\mathrm{k}}$ & $0.82^{k}$ & $-1.5^{\mathrm{k}}$ & - & - & - & - & - & - \\
\hline
\end{tabular}

a Yoshino et al. (2009).

b Yoshino et al. (2012).

c Yoshino and Katsura (2012a, 2012b).

d Yoshino et al. (2008a).

e Zhang and Yoshino (2016).

f Zhang et al. (2012).

$\mathrm{g}$ Zhao and Yoshino (2016), assuming data from high Hact regime is suitable for mantle temperature.

${ }^{\mathrm{h}}$ Yoshino et al. (2008b), values for low-Fe majorite with three different temperature ranges: below $1300 \mathrm{~K}$, intermediate and above $1800 \mathrm{~K}$. Note that the later regime may be attributed to ionic conduction.

${ }^{\mathrm{i}}$ Yoshino et al. (2016), average $\sigma_{0}$ value for Arrhenius fit on Fig. 2 for activation volume of $-0.3 \mathrm{~cm}^{3} / \mathrm{mol}$ and activation enthalpy of $0.49 \mathrm{eV}$ at $27 \mathrm{GPa}$ (Table 2 ).

${ }^{\mathrm{j}}$ Yoshino et al. (2011).

${ }^{\mathrm{k}}$ Katsura et al. (2007).

the magnetic field increases with the period, study of transfer functions, or equivalently Gauss coefficients $l_{1}^{0}(\omega)$, at different frequencies will allow to sound the different layers. The analysis of the whole set of Fourier coefficients will therefore provide estimates of 1D conductivity profiles in the mantle, or temperature profiles if a given composition is assumed.

\section{Electrical conductivity of hydrous silicates}

At pressure and temperature relevant to the Earth's mantle, the electrical conductivity $\sigma$ of an hydrous silicate is the sum of three different conduction mechanisms (e.g. Yoshino (2010)):

$\sigma=\sigma_{i}+\sigma_{h}+\sigma_{p}$

where $\sigma_{i}$ is the ionic conduction associated to the migration of Mgvacancies sites, $\sigma_{h}$ corresponds to the small polaron conduction related to electron holes hopping between ferrous and ferric iron, and $\sigma_{p}$ is the proton conduction defined by the migration of protons. All these three different conduction mechanisms increase with temperature according to an Arrhenius law:

$\sigma_{i, h, p}=\sigma_{0}^{i, h, p} \exp \left(\frac{-\Delta H_{i, h, p}}{k T}\right)$

where $\sigma_{0}$ is the pre-exponential factor, $\Delta H$ the activation enthalpy, $k$ the Boltzmann's constant and $T$ the absolute temperature.

Proton conduction is governed by water content whereas iron content governs small polaron conduction. Both the pre-exponential factor and the activation enthalpy depend on the density of charge carriers. This dependence is however controversial among the different research groups that have measured the electrical conductivity of hydrous mineral phases (see Yoshino (2010), Karato (2011), Gardés et al. (2014), or Fullea (2017) for recent reviews). In this work, we used the results of the Yoshino group which offer the most complete database for the conductivity of all mineral phases. Except for ferropericlase, all the measurements performed by this group are well modelled by the general equation:

$$
\begin{gathered}
\sigma=\sigma_{0}^{i} \exp \left(-\frac{\Delta E_{i}+P \Delta V_{i}}{k T}\right) \\
+\sigma_{0}^{h} X_{F e} \exp \left(-\frac{\left(\Delta E_{h}-\alpha_{h} X_{F e}^{1 / 3}\right)+P\left(\Delta V_{h}-\beta_{h} X_{F e}\right)}{k T}\right) \\
+\sigma_{0}^{p}\left(C_{w}\right)^{r_{p}} \exp \left(-\frac{\Delta H_{p}-\alpha_{p} C_{w}^{1 / 3}}{k T}\right)
\end{gathered}
$$

where $\sigma_{0}^{i, h}, p, \Delta E_{i, h}$ and $\Delta H_{p}$ are the pre-exponential factor, activation energy for ionic or small polaron conduction, and activation enthalpy for proton conduction, respectively, $X_{F e}$ is the mole fraction of Fe in the $\mathrm{Mg}$ site, $C_{w}$ is water content (in wt $\%$ ) in the sample, $\alpha_{h, p}, \beta_{h}$ and $r_{p}$ are coefficients governing the effect of iron and water content on small polaron and proton conduction, $\Delta V_{i, h}$ are activation volumes for ionic and small polaron conduction, respectively, and $P$ is pressure. All $\sigma_{0}^{i} h, p$, $\Delta E_{i, h, p}, \Delta V_{i, h}, \alpha_{h, p}, \beta_{h}$ and $r_{p}$ coefficient values are different for each mineral phase. Such values are reported on Table 1 for the nine mineral phases used in this study. Note that for ferropericlase, the small polaron conductivity is fitted by the equation

$\sigma=\sigma_{0}^{h} X_{F e} \exp \left(-\frac{\left(\Delta E_{h}-\alpha_{h} X_{F e}^{1 / 3}\right)+P\left(\Delta V_{h}-\beta_{h} X_{F e}^{1 / 3}\right)}{k T}\right)$

To model proton conduction for olivine, pyroxenes, wadsleyite and ringwoodite, their water content has to be estimated. The water content $C_{w}^{i}$ of upper mantle mineral phase $i$, in weight, is related to the bulk rock water content $C_{w}$ through the mass conservation equation

$C_{w}=\sum_{\text {phases } i} x_{i} C_{w}^{i}$

where $x_{i}$ is the mass fraction of upper mantle phase $i$ (olivine, orthopyroxene, clinopyroxene, garnet, wadsleyite and ringwoodite). Each water content $C_{w}^{i}$ can be computed from olivine water content $C_{w}^{o l}$ using the water partition coefficients $D_{H 2 O}^{i / o l}$ which govern how water is distributed among mantle minerals $i$ compared to olivine. For pyroxene 

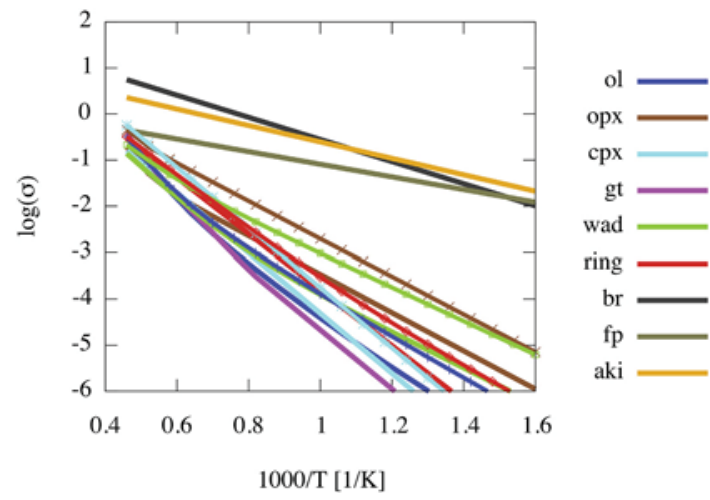

Fig. 3. Laboratory-based electrical conductivity as a function of inverse temperature for all mineral phases of the Earth's mantle: olivine (ol), orthopyroxene (opx), clinopyroxene (cpx), garnet (gt), wadsleyite (wad), ringwoodite (ring), for a pressure of $10 \mathrm{GPa}$, and bridgmanite (br), ferropericlase (fp) and akimotoite (aki), for a pressure of $30 \mathrm{GPa}$. Solid lines correspond to samples with $100 \mathrm{ppm}$ water content whereas lines with symbols represent samples with 500 ppm water content.

and garnet, we use the partition coefficient values from Novella et al. (2014) $D_{H 2 O}^{o p x} \times{ }^{o l}=1.9, D_{H 2 O}^{c p x} / o l=3.2$ and $D_{H 2 O}^{\text {ot }} / 0 \mathrm{O}=0.8$, whereas the results of Inoue et al. (2010) are used for wadsleyite and ringwoodite, $D_{H 2 O}^{w a d / o l}=5$ and $D_{H 2 \mathrm{O}}^{\text {ring }}{ }^{\mathrm{wad}}=0.5$.

Fig. 3 represents laboratory-based electrical conductivity as a function of temperature for all mineral phases of the Earth's mantle: olivine, orthopyroxene, clinopyroxene, garnet, wadsleyite, ringwoodite, for a pressure of $10 \mathrm{GPa}$ and bridgmanite, ferropericlase and akimotoite, for a pressure of $30 \mathrm{GPa}$. Solid lines correspond to samples with $100 \mathrm{ppm}$ water content whereas lines with symbols represent samples with 500 ppm water content. Note that this modelling goes well beyond the stability field of each mineral phase. Bridgmanite, ferropericlase and akimotoite present larger conductivity than upper mantle minerals in the whole temperature range. At lower mantle conditions, bridgmanite is the most conductive mineral phase, reaching a conductivity of about 10 $\mathrm{S} / \mathrm{m}$ at $2500 \mathrm{~K}$. Variability among the conductivity of the upper mantle phases decreases with temperature, with two orders of magnitude around $800 \mathrm{~K}$ and less than one order at $2000 \mathrm{~K}$. At temperature lower than $1000 \mathrm{~K}$, orthopyroxene is the most conductive mineral whereas garnet displays the lowest conductivity. Among all mineral phases whose electrical conductivity involves proton conduction, ringwoodite is the less sensitive to water content. For all minerals, the water content dependance decreases with temperature, in relation to the decrease of proton conduction mechanism compared to ionic and small polaron conductions (see e.g. Yoshino (2010)). Note that the conductivity of upper mantle phases, i.e. olivine, pyroxenes, garnet, wadsleyite and ringwoodite depends more largely on temperature than those of lower mantle phases, i.e. bridgmanite, ferropericlase and akimotoite. For a given composition, electrical conductivity can therefore be considered as a more reliable proxy for temperature in the upper mantle than in the lower mantle.

Panel b of Fig. 4 shows the comparison between a laboratory-based conductivity profile computed with this database along with different conductivity profiles derived from global induction studies. The laboratory-based conductivity profile for the Earth's mantle is computed from Stacey and Davis (2008) temperature profile, Irifune (1987) pyrolite composition, and a water content assumed to be equal to $0.01 \%$ in the upper mantle and $0.1 \%$ in the mantle transition zone, in agreement with both geochemical analysis of basalts and geophysical study of electrical conductivity reported by Karato (2011). Pressure is assumed to be identical to PREM (Dziewonski and Anderson, 1981) values and the mineralogical transformations are computed at each pressure/temperature conditions according to phase diagrams discussed in Vacher et al. (1998) for dry mineralogy. Conductivity of the rock aggregate is (a)

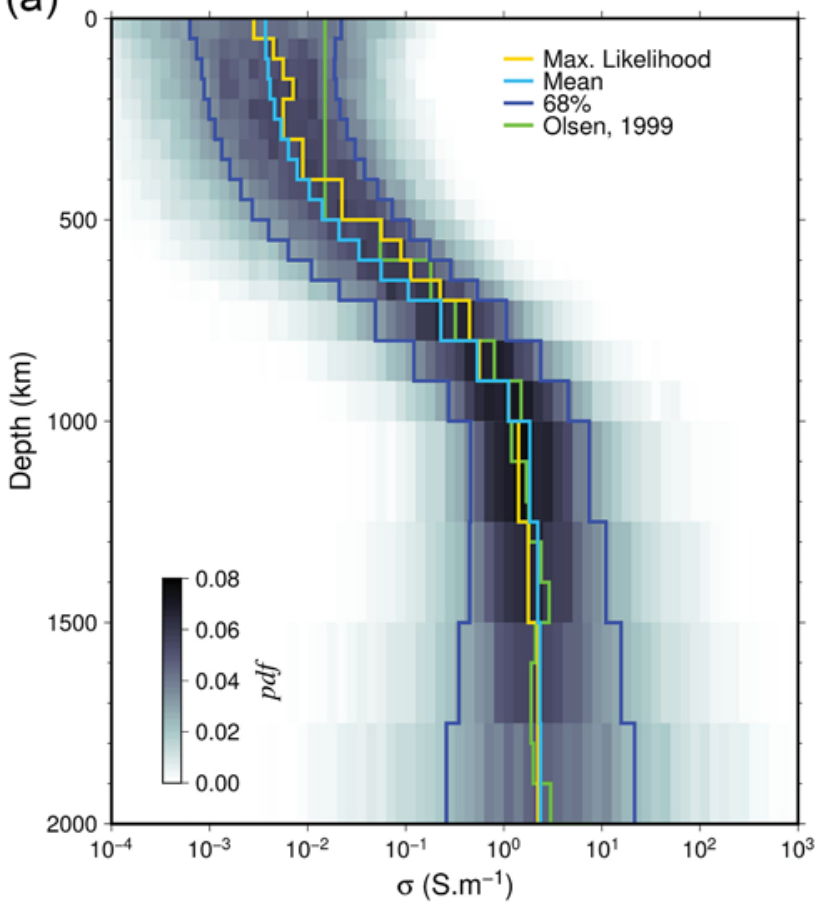

(b)

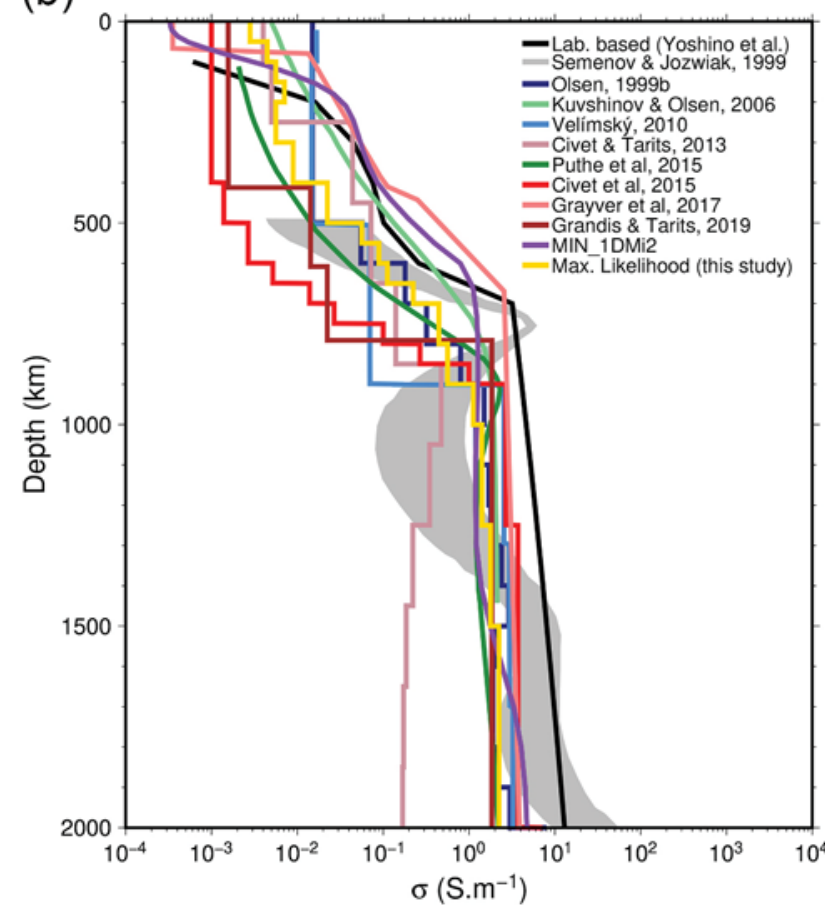

Fig. 4. Panel a: Probability density function of electrical conductivity profile obtained from the inversion of Gauss coefficients $l_{1}^{0}(\omega)$. The maximum likelihood and mean curves are in orange and light blue, respectively. The $68 \%$ confidence curve is in blue. The result of Olsen (1999b) is shown for comparison. Panel b: Yoshino and collaborators laboratory-based versus geophysicallybased conductivity profiles of Semenov and Jozwiak (1999), Olsen (1999b), Kuvshinov and Olsen (2006), Velímský (2010), Civet and Tarits (2013), Püthe et al. (2015), Civet et al. (2015), Grayver et al. (2017), Grandis and Tarits (2019), the model MIN_1D L2 (ESA Swarm Level2 product) and the maximum likelihood profile derived in this work. (For interpretation of the references to colour in this figure legend, the reader is referred to the web version of this article.) 
computed as the effective medium average (Landauer, 1952) of individual mineral phase conductivity $\sigma$ modelled by Eqs. (5) and (6) with parameters values from Table 1 . In the depth range [200 km, $600 \mathrm{~km}$ ], the laboratory-based profile is very close (less than $0.25 \log$ unit) to the profile derived by Kuvshinov and Olsen (2006) and presents intermediate values between the data-based profiles of Olsen (1999b) and Grayver et al. (2017), whereas in the lower mantle, the laboratory-based profile is larger than all of the data-derived profiles and increases with depth in relation to the high value for activation volumes of lower mantle phases reported in Table 1.

\section{Estimation of the radial mantle electrical conductivity and temperature profiles}

In this work, we use the Bayesian inversion of spectra of induced coefficients $l_{1}^{0}(\omega)$ to estimate the probability distribution of the electrical conductivity or temperature profiles. One of the main advantages of this strategy is that it relies on the forward problem only. During the Bayesian approach inversion, the forward problem is used to estimate the internal response $l_{1 \text {,model }}^{0}(\omega)=Q_{1}(\omega) \varepsilon_{1}^{0}(\omega)$ of a conductive medium. The algorithm takes a spherical semi-infinite medium of high electrical conductivity at the core mantle boundary and goes upward through $L$ successive conductive layers to estimate the induced response in terms of internal potentials for the considered frequencies $\omega$ (Srivastava, 1966). These layers are characterized by their thickness and either their electrical conductivity or their temperature, for a given pyrolite composition and water content. In order to accommodate the decrease in resolution with depth, 21 layers were chosen to estimate the conductivity: 14 layers of $50 \mathrm{~km}$ thickness between 0 and $700 \mathrm{~km}$ depth, 3 layers of $100 \mathrm{~km}$ thickness between 700 and $1000 \mathrm{~km}$ and 4 layers of $250 \mathrm{~km}$ thickness between 1000 and $2000 \mathrm{~km}$ depth.

Within the Bayesian framework, the inverse problem consists in estimating marginal probability distributions for the conductivity, or temperature. Such distribution are best sampled by random walks

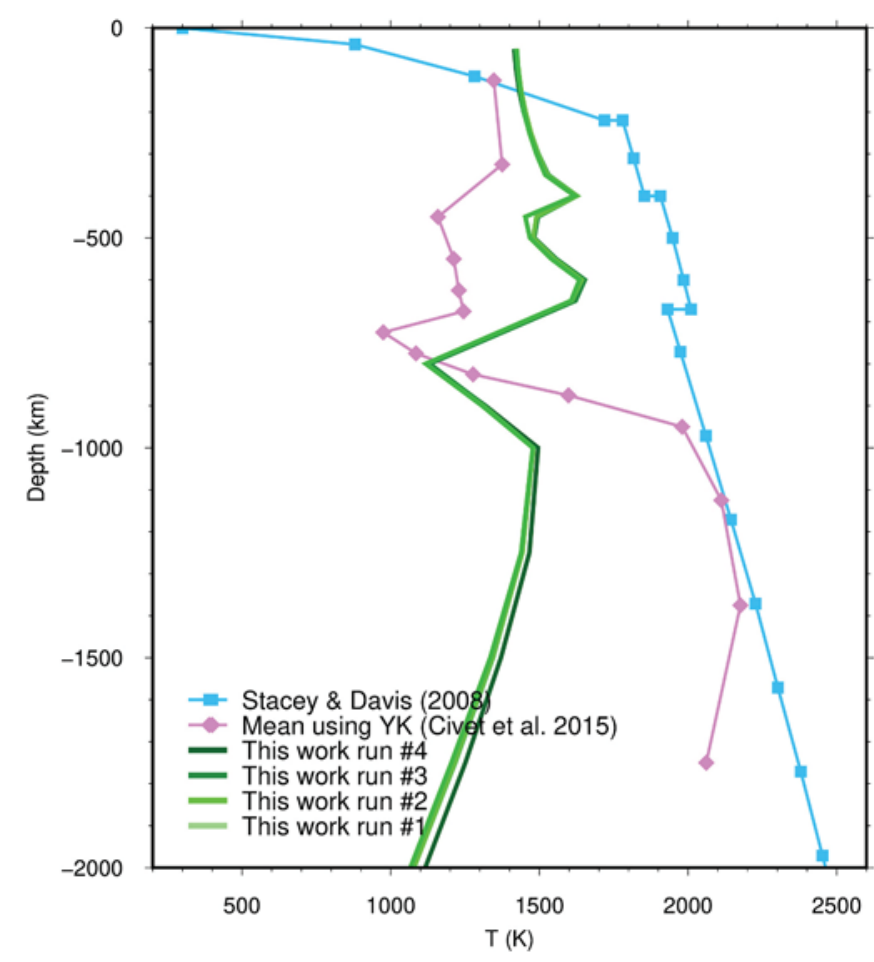

Fig. 5. Temperature profiles associated to the four Markov chains used to sample the posterior distribution of the electrical conductivity shown in Fig. 4. The Stacey and Davis (2008) temperature profile and the Civet et al. (2015) temperature profile are shown for comparison. known as Markov chain during which model parameters are randomly updated at each iteration according to a transition probability. Such transition probability is based on a $\chi^{2}$ function computed as a compromise between the likelihood that measures the misfit between real data $l_{1}^{0}(\omega)$ and synthetic data $l_{1, \text { model }}^{0}(\omega)$ computed from parameter models and the prior probability that represents any a priori knowledge on the parameters.

For an inversion in terms of conductivity, the $\chi^{2}$ function is given by

$\chi^{2}=\sum_{\omega}^{N_{\omega}}\left[\log _{10}\left(\left|l_{1}^{0}(w)\right|\right)-\log _{10}\left(\left|l_{1, \text { model }}^{0}(w)\right|\right)\right]^{2}+\lambda_{\sigma} \sum_{l=1}^{L-1}\left|\log _{10}\left(\sigma_{l}\right)-\log _{10}\left(\sigma_{l+1}\right)\right|$

where $N_{\omega}$ is the number of frequencies used, $L$ is the number of layers and $\lambda_{\sigma}$ is a prior coefficient.

For an inversion in terms of temperature, only the prior is modified and the $\chi^{2}$ function is modified as

$\chi^{2}=\sum_{\omega}^{N_{\omega}}\left[\log _{10}\left(\left|l_{1}^{0}(w)\right|\right)-\log _{10}\left(\left|l_{1, \text { model }}^{0}(w)\right|\right)\right]^{2}+\lambda_{T} \sum_{l=1}^{L-1}\left|\log _{10}\left(T_{l}\right)-\log _{10}\left(T_{l+1}\right)\right|$

where $\lambda_{T}$ is a prior coefficient.

The number $N_{\omega}$ of frequencies used in this study is 1113 ( 0 frequency is removed), uniformly sampled between $2227^{-1}$ and 0.5 days $^{-1}$.

The second term of Eqs. (8) and (9) is designed to smooth the conductivity or temperature contrasts between two consecutive layers with a damping parameter $\lambda$. The value of the $\lambda$ coefficient was tuned during test cases in order to lead to optimal balance between misfit and prior. High values of $\lambda_{\sigma}$ lead to strong smoothing coefficients which prevent the increase of conductivity with depth, and very small values of $\lambda_{\sigma}$ lead to slow convergence of the Markov chain. Optimal value of $\lambda_{\sigma}$ equal to 1 was found, which corresponds to a prior equal to $30 \%$ of the misfit value. Similar test cases were performed for the inversion of $l_{1}^{0}(\omega)$ in terms of temperature, leading to an optimal $\lambda_{T}$ value equal to 10 , and corresponding to a prior equal to $80 \%$ of the misfit value.

The posterior marginal probability distribution is explored through a Markov process based upon a Metropolis sampler of the conductivity or temperature values. The transition probability was designed to obtain acceptance rate between 25\% and 50\% (Gelman, 1996).

\section{Inversion of Gauss coefficients $l_{1}^{0}(\omega)$ estimated from Swarm data}

\subsection{Estimation of the radial mantle electrical conductivity profile}

Panel a of Fig. 4 shows the results of the inversion of Gauss coefficients $l_{1}^{0}(\omega)$ estimated from Swarm data in terms of the electrical conductivity in the range $\left[10^{-4} \mathrm{~S} / \mathrm{m}, 10^{3} \mathrm{~S} / \mathrm{m}\right]$. After 10,000 cold runs, designed to allow the inversion procedure to forget the arbitrary initial state, marginal probabilities were computed from the sampling of 4 different Markov chains performing 200,000 iterations each. To decrease the coherence between successive samples, the sampling was performed every 100th runs. The uncertainty increases with depth, as seen from wider probability distribution. Indeed, the Fourier analysis leads to uniform sampling in frequency domain, which corresponds to non uniform sampling in period. As the penetration depth $\delta$ of the geomagnetic field inside a layer of constant conductivity $\sigma$ is a function of the square-root of the period (see Eq. (2)), the very small number of long periods constrain only marginally depths larger than $1500 \mathrm{~km}$. The mean and maximum likelihood profiles are very close, with a maximum difference of $0.5 \log$ unit in the transition zone. These profiles present three distinct behaviors: a 0.6-0.7 log unit increase between 0 and 500 $\mathrm{km}$ depth followed by a sharp increase of $2 \log$ unit between 500 and $1000 \mathrm{~km}$ and a roughly constant value of $10^{0.25} \mathrm{~S} / \mathrm{m}$ for larger depths. 


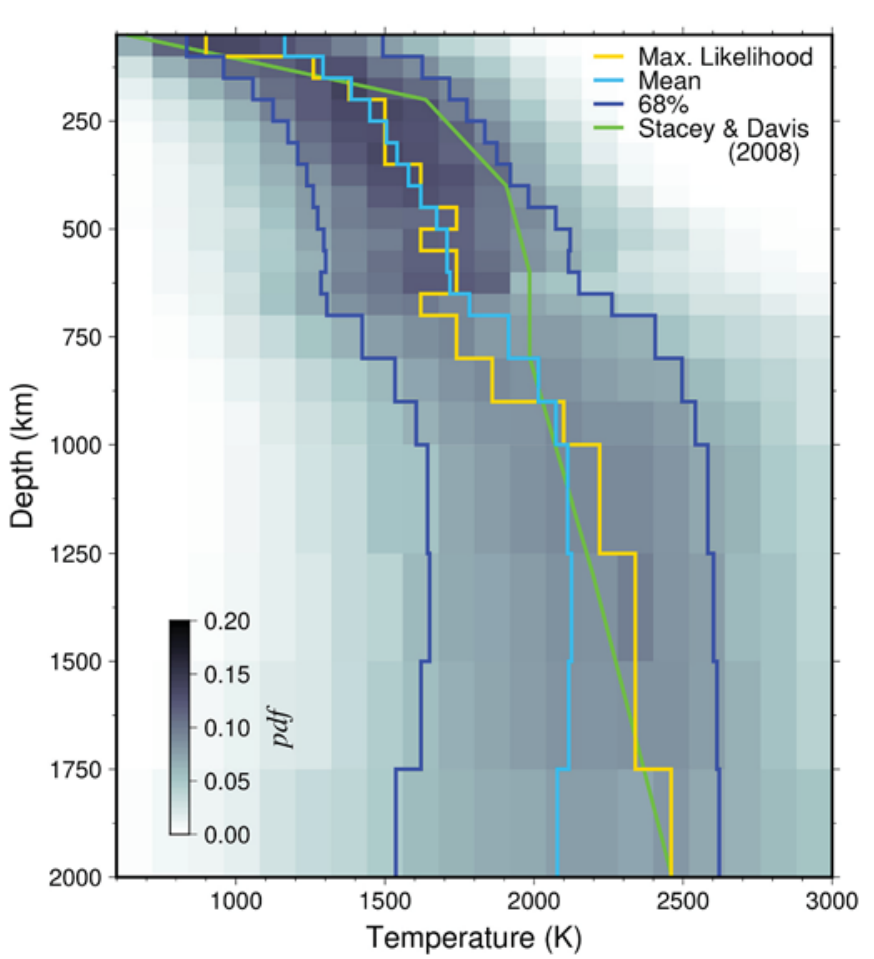

Fig. 6. Probability density function of temperature profile obtained from the inversion of Gauss coefficients $l_{1}^{0}(\omega)$, assuming pyrolite composition and a water content of $0.01 \%$ in the upper mantle and $0.1 \%$ in the mantle transition zone. The temperature profile of Stacey and Davis (2008) is shown for comparison.

Panel b of Fig. 4 shows the comparison between the profile corresponding to the maximum likelihood probability with the different profiles published in the last 20 years. This profile is very close to the profile of Puithe et al. (2015) obtained from 10 years of magnetic measurements from the Ørsted, CHAMP, SAC-C and Swarm satellites and the global network of geomagnetic observatories and to the profile of Olsen (1999b) based on daily mean values recorded at 42 European observatories during 50 years. In the lower mantle, no conductivity profile derived from induction studies present an increase of the conductivity with depth compatible with the laboratory-based conductivity profile computed with the database of Table 1. As this profile was computed with the classical assumptions about composition, water content and temperature profiles, the origin of this discrepancy relies probably on the database used to model the conductivity of the mineral phases of the lower mantle. These measurements are indeed particularly complicated to obtain at the extreme pressure and temperature conditions of this region.

\subsection{Estimation of temperature: inversion of conductivity versus inversion of Gauss coefficients}

For given composition and water content in the mantle, a temperature estimate can be directly derived from an electrical conductivity profile by standard numerical root search. Such method was used by Civet et al. (2015) to compute temperature profiles associated to conductivity profiles estimated by a Bayesian inversion of Gauss coefficients $l_{1}^{0}(\omega)$. The same method was applied to the conductivity profiles obtained in the previous section and the results are shown in Fig. 5. In most of the mantle, the temperature profile derived is largely underestimated. This underestimation is related to the very high values of laboratorybased conductivity. Indeed, as the discrepancy between laboratorybased and magnetic data-based conductivity (Panel b of Fig. 4) is interpreted in terms of temperature only, lower temperature values are required in the laboratory-based profile to fit the magnetic-data derived

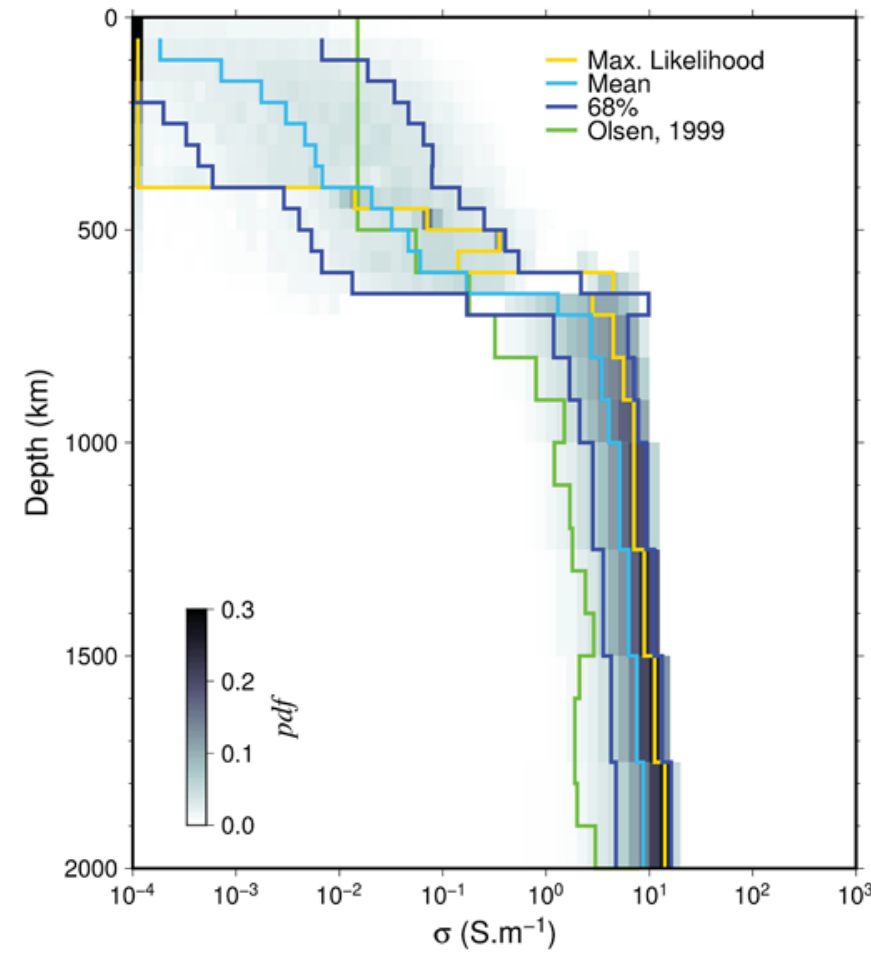

Fig. 7. Electrical conductivity probability density function computed from the temperature probability density function of Fig. 6. Electrical conductivity profile of Olsen (1999b) is shown for comparison.

conductivity. This effect is increased by the small sensitivity of the conductivity of lower mantle phases with temperature.

The forward problem described in Section 4 can also be used in the inversion scheme to infer probability distribution directly in terms of temperature, assuming pyrolite composition and a water content of $0.01 \%$ in the upper mantle and $0.1 \%$ in the mantle transition zone. One advantage of the inversion directly in terms of temperature is that it allows to anchor the prior on the surface temperature value of $298 \mathrm{~K}$. This value will remain fixed for the first layer during the inversion process and only 20 temperature values are estimated. The conductivity value for the first layer is also fixed to Olsen (1999b) value.

Fig. 6 shows the results of the inversion of Gauss coefficients $l_{1}^{0}(\omega)$ estimated from Swarm data in terms of temperature in the range [600 K, $3000 \mathrm{~K}$ ], with the same inversion scheme as for the conductivity $(10,000$ cold runs, 4 chains with 200,000 main runs each, sampling every 100ths runs). Due to smaller sensitivity of conductivity to temperature for lower mantle phases, the temperature probability distribution is larger in this region with a smaller resolution balanced by the prior values which favor constant values. The mean and maximum likelihood profiles differ by less than $250 \mathrm{~K}$, except at depths shallower than $200 \mathrm{~km}$ and larger than $1250 \mathrm{~km}$. The mean and maximum likelihood profiles present a similar evolution with depth to the geotherm of Stacey and Davis (2008) with about $300 \mathrm{~K}$ colder temperatures in the $[250,750] \mathrm{km}$ depth range. In the lower mantle, the maximum likelihood differs by less than $200 \mathrm{~K}$ with the geotherm, although the mean profile remains constant. This could be a consequence of the a priori considered temperature interval, which prohibits extreme temperatures larger than $3000 \mathrm{~K}$.

The inversion directly in terms of temperature considerably increases the reliability of the results, in relation to physically-grounded temperature range and prior values. Through the prior smoothing on the temperature profile, such inversion scheme prevents the rapid variations of the temperature profile observed in Fig. 5 and induced by the many phase transitions present at depths smaller than $1000 \mathrm{~km}$. As the decrease of resolution with depth affects both the inversion in terms of conductivity and the inversion in terms of temperature, the prior values 
(a)

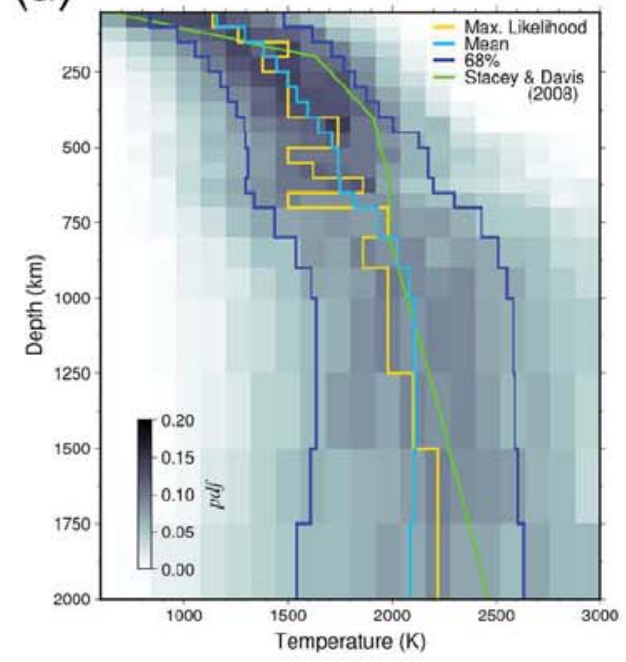

(c)

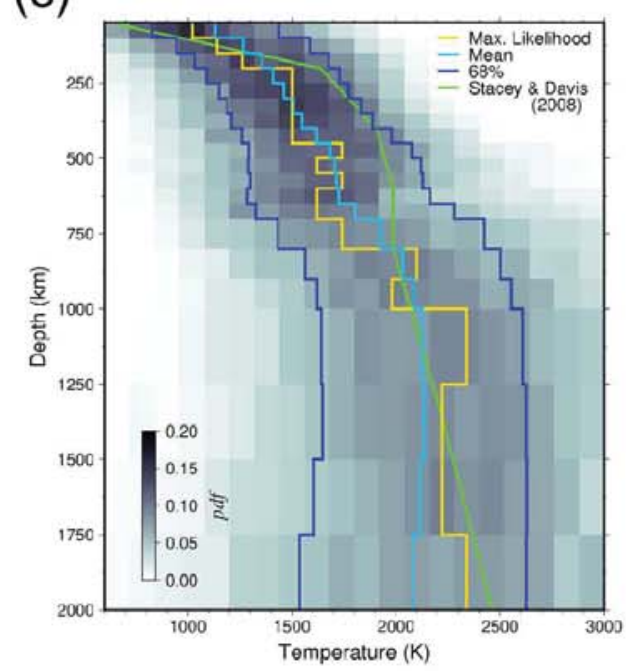

(e)

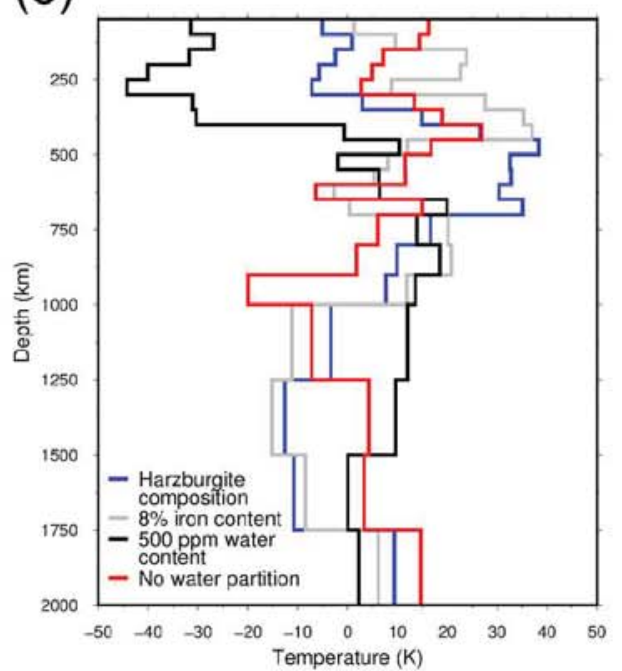

(b)

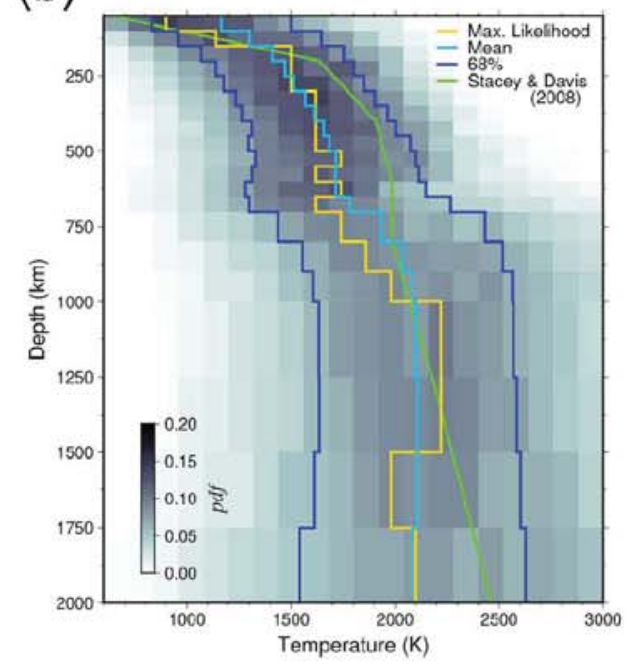

(d)

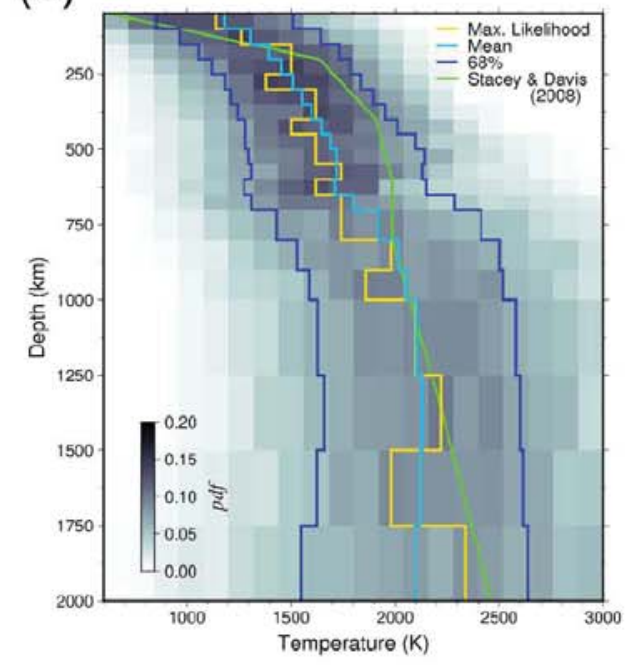

(f)

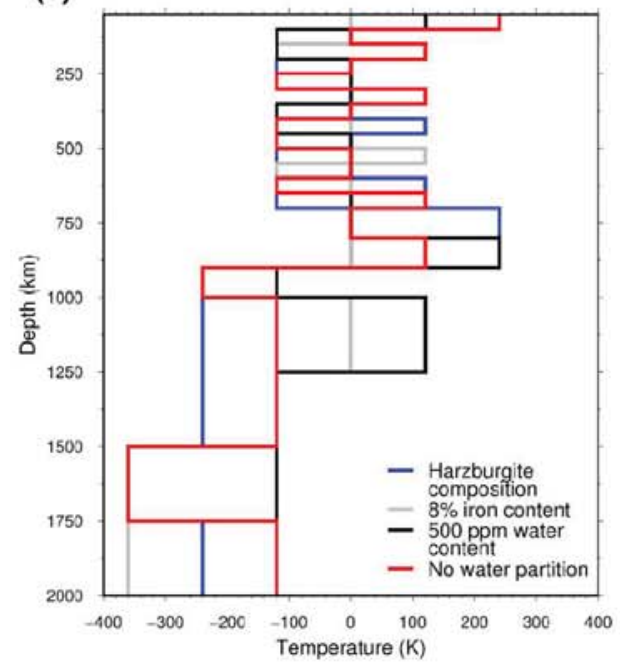

Fig. 8. Probability density function of temperature profile obtained from the inversion of Gauss coefficients 
drive the inversion results for depths greater than $1500 \mathrm{~km}$. Tempera ture estimates in this region are therefore more reliable when derived directly from Gauss coefficients as they prevent the effect on a less physically grounded smoothing on conductivity which leads to strong underestimated values in relation to the small sensitivity to temperature of the conductivity of lower mantle phases.

The forward problem can be used to compute the a posteriori probability density function (pdf) of the electrical conductivity associated to the temperature pdf. Such results are shown on Fig. 7. Compared to the conductivity pdf obtained from an inversion in terms of electrical conductivity (panel a of Fig. 4), the conductivity pdf from the inversion in terms of temperature is much more diffuse in the upper mantle and narrower in the lower mantle. This is related to the very different sensitivity of the electrical conductivity of mineral phases of upper and lower mantle phases with respect to temperature (see Fig. 3). This effect is also increased by the numerous phase transitions that can arise in the upper mantle and that can cause sharp variations of the conductivity. Mantle electrical conductivity is therefore best constrained in the upper mantle from inversion in terms of conductivity (due to the many mineral phases involved) and best constrained in the lower mantle from inversion in terms of temperature (due to the limited variation of conductivity in the lower mantle temperature range).

To estimate the effect on mineralogical composition, iront content, water content, and water partition coefficients, on the interpretation of Swarm data in terms of temperature, we performed complementary inversions, varying in turn each parameter with respect to the reference case described above (pyrolite composition and a water content of $0.01 \%$ in the upper mantle and $0.1 \%$ in the mantle transition zone).

For the mineralogical composition, the harzburgite model for subducted oceanic lithosphere, characterized by a very high olivine content of $82 \%$ (Cammarano et al., 2003) can be considered as an end-member of the diversity of mantle models with the same iron content. In order to explore the effect of iron content, we consider an additional pyrolite model with a $4 \%$ decrease in the Fe-content (from $\mathrm{Mg} \#=88$ to 92), and the same water content. A third model, with water content equal to 500 ppm for the whole mantle and a pyrolite composition with $12 \%$ iron content has been tested to estimate the sensitivity of our temperature interpretation to this parameter. Finally, a fourth inversion was performed with no water partition.

Fig. 8 shows the results of these inversion, along with a comparison of the four mean curves with the reference case. The four mean curves differ from the reference case by less than $50 \mathrm{~K}$ in the whole mantle. The similarity of these results is likely related to the combination of a prior that imposes a $298 \mathrm{~K}$ temperature at the surface and of very similar conductivity values for mineral phases at the temperature range of the lower mantle (see Fig. 3). Note that the conductivity of lower mantle phases does not depend on water content or water partitioning as it is modelled by small polaron conduction only (see Table 1). Discrepancies are larger for the maximum likelihood curves, especially in the lower mantle, where the probality distribution is wider and presents many local maximum values.

\section{Conclusions}

This work presents a full analysis and interpretation in terms of electrical conductivity and temperature of vector magnetic field measurements from Swarm Level1b data product from 26/11/2013 to 31/ $12 / 2019$. All the process is performed and designed to ensure coherence throughout the whole data processing and to obtain the most reliable information on Earth's mantle structure from the largest set of Swarm data available so far. The core and lithospheric fields are removed from the data and time series of the Gauss coefficients associated with the induced and inducing parts of the residuals are computed. A Bayesian inversion is used to solve the global induction problem and provides a new estimate of Earth's mantle electrical conductivity. The maximum likelihood probability profile is very close to the profiles derived by
Olsen (1999b) and Püthe et al. (2015) but does not present in the lower mantle the increase predicted by laboratory-based conductivity profile associated to classical mantle composition and temperature profile. Using the most recent database to model the electrical conductivity of all mineral mantle phases, two different methods are used to interpret Swarm data in terms of temperature for a given composition and water content. The first one was used in Civet et al. (2015) and is based on an interpretation of the conductivity estimates in terms of temperature by classical numerical root search. The second one consists in inferring a temperature probability density function from a Bayesian inversion of the Gauss coefficients associated to the induced magnetic field. Our results show that the latter provide more reliable estimates of mantle temperatures, in relation to more physically grounded prior values. This second method provides also tighter constraints on the electrical conductivity estimates of the lower mantle.

As this work is based on Swarm data only, it demonstrates the ability of such data to provide a new estimate of the electrical conductivity profile of the Earth's mantle and thermal state. The robustness of our conductivity and thermal profiles in the $[0,1500 \mathrm{~km}]$ depth range will increase with the length of the Gauss coefficients time series in relation to the growing number of Fourier harmonics relevant to sound this region. However, resolution will remain limited in relation to the difficulty to discriminate secular variation and induced field contributions in the magnetic field signal. The reliability of our interpretation in terms of temperature relies on the database used to model the conductivity and will increase with the accuracy of the high pressure and high temperature laboratory measurements of electrical conductivity of mineral phases.

Further works include the opportunity to perform joint inversion with geodetic or seismological data to go beyond the assumption on composition and water content and infer decorrelated information on composition and temperature. Other perspectives include to go beyond the $P_{1}^{0}$ geometry and to complement magnetoscphetic signals by new sources such as tidal geomagnetic field variations (Grayver et al., 2017; Grayver and Olsen, 2019) which provide complementary and tighter constrains on lithosphere and upper mantle conductivity.

\section{Declaration of Competing Interest}

The authors declare that they have no known competing financial interests or personal relationships that could have appeared to influence the work reported in this paper.

\section{Acknowledgments}

The authors thank Gabrielle Hellio for her preliminary work on the data processing. The authors acknowledge ESA for providing access to Swarm Level 1b products, which are freely available by FTP to ESA-EO registered users (for access details, see https://earth.esa.int/web/gues t/swarm/data-access). The authors acknowledge GFZ Potsdam (https ://www.gfz-potsdam.de/en/kp-index/), WDC Kyoto (http://wdc.kugi. kyoto-u.ac.jp/dstae/index.html) and NASA OMNIWEB service (https ://omniweb.gsfc.nasa.gov/form/dx1.html) for the access to geomagnetic indices.

The authors are very grateful to the Editor Dominique Jault and two anonymous reviewers for their very constructive remarks.

This work was supported by ESA Swarm Data, Innovation and Science Cluster (Swarm DISC) program and partially supported by CNES within the the project "Exploitation des mesures de la mission Swarm".

\section{References}

Astafyeva, E., Zakharenkova, I., Förster, M., 2015. Ionospheric response to the 2015 St Patrick's Day storm: a global multi-instrumental overview. J. Geophys. Res. Space Physics 120 (10), 9023-9037.

Banks, R.J., 1969. Geomagnetic variations and the electrical conductivity of the upper mantle. Geophys. J. 17, 457-487. 
Birch, F., 1952. Elasticity and constitution of the earth's interior. J. Geophys. Res. (1896-1977) 57 (2), 227-286. https://doi.org/10.1029/JZ057i002p00227.

Cammarano, F., Goes, S., Vacher, P., Giardini, D., 2003. Inferring upper-mantle temperatures from seismic velocities. Phys. Earth Planet. Inter. 138 (3-4), 197-222.

Cammarano, F., Goes, S., Deuss, A., Giardini, D., 2005. Is a pyrolitic adiabatic mantle compatible with seismic data? Earth Planet. Sci. Lett. 232 (3-4), 227-243.

Civet, F., Tarits, P., 2013. Analysis of magnetic satellite data to infer the mantle electrical conductivity of telluric planets in the solar system. Planet. Space Sci. 84, 102-111.

Civet, F., Thébault, E., Verhoeven, O., Langlais, B., Saturnino, D., 2015. Electrical conductivity of the Earth's mantle from the first swarm magnetic field measurements. Geophys. Res. Lett. 42, 3338-3346.

Cobden, L., Goes, S., Ravenna, M., Styles, E., Cammarano, F., Gallagher, K., Connolly, J. A.D., 2009. Thermochemical interpretation of 1-d seismic data for the lower mantle: the significance of nonadiabatic thermal gradients and compositional heterogeneity. J. Geophys. Res. Solid Earth 114 (B11). https://doi.org/10.1029/2008JB006262.

Constable, S., 2015. Geomagnetic induction studies. In: Schubert, G., Kono, M. (Eds.), Treatise on Geophysics, Volume 5, second edition. Elsevier, pp. 219-254. Ch. 7.

Constable, S., Constable, C., Jan 2004. Observing geomagnetic induction in magnetic satellite measurements and associated implications for mantle conductivity. Geochem. Geophys. Geosyst. 5. http://www.agu.org/journals/gc/gc0401/200 3GC000634/2003GC000634.pdf.

da Silva, C.R., Wentzcovitch, R., Patel, A., Price, G., Karato, S., 2000. The composition and geotherm of the lower mantle: constraints from the elasticity of silicate perovskite. Phys. Earth Planet. Inter. 118 (1), 103-109. http://www.sciencedirect.co $\mathrm{m} /$ science/article/pii/S0031920199001338.

Deschamps, F., 2015. Lower mantle electrical conductivity inferred from probabilistic tomography. Terr. Atmos. Ocean. Sci. 26, 27-40.

Deschamps, F., Khan, A., 2016. Electrical conductivity as a constraint on lower mantle thermo-chemical structure. Earth Planet. Sci. Lett. 450, 108-119.

Deschamps, F., Trampert, J., 2004. Towards a lower mantle reference temperature and composition. Earth Planet. Sci. Lett. 222 (1), 161-175.

Dziewonski, A.M., Anderson, D.L., 1981. Preliminary reference Earth model. Phys. Earth Planet. Inter. 25, 297-356.

Finlay, C.C., Lesur, V., Thébault, E., Vervelidou, F., Morschhauser, A., Shore, R., 2017. Challenges handling magnetospheric and ionospheric signals in internal geomagnetic field modelling. Space Sci. Rev. 206 (1-4), 157-189.

Fullea, J., 2017. On joint modelling of electrical conductivity and other geophysical and petrological observables to infer the structure of the lithosphere and underlying upper mantle. Surv. Geophys. 38, 963.

Gardés, E., Gaillard, F., Tarits, P., 2014. Toward a unified hydrous olivine electrical conductivity law. Geochem. Geophys. Geosyst. 15 (12), 4984-5000. https://doi.org/ 10.1002/2014GC005496.

Gelman, A., 1996. Inference and monitoring convergence. In: Gilks, S., Richardson, D.S. (Eds.), W. Markov Chain Monte Carlo in Practice, Chapman \& Hall/CRC Interdisciplinary Statistics, pp. 131-143.

Grandis, H., Tarits, P., 2019. Bayesian inversion for layered spherical symmetric earth conductivity model from global magnetic data. IOP Conf. Ser. Earth Environ. Sci. 318, 012003 https://doi.org/10.1088/1755-1315/318/1/012003.

Grayver, A.V., Olsen, N., 2019. The magnetic signatures of the $\mathrm{M}_{2}, \mathrm{~N}_{2}$, and $\mathrm{O}_{1}$ oceanic tides observed in Swarm and CHAMP satellite magnetic data. Geophys. Res. Lett. 46 (8), 4230-4238.

Grayver, A.V., Munch, F.D., Kuvshinov, A.V., Khan, A., Sabaka, T.J., Tøffner-Clausen, L., 2017. Joint inversion of satellite-detected tidal and magnetospheric signals constrains electrical conductivity and water content of the upper mantle and transition zone. Geophys. Res. Lett. 44, 6074-6081.

Inoue, T., Wada, T., Sasaki, R., Yurimoto, H., 2010. Water partitioning in the Earth's mantle. Phys. Earth Planet. Inter. 183, 245-251.

Irifune, T., May 1987. An experimental investigation of the pyroxene-garnet transformation in a pyrolite composition and its bearing on the constitution of the mantle. Phys. Earth Planet. Inter. 45, 324-336.

Jackson, I., 1998. Elasticity, composition and temperature of the Earth's lower mantle: a reappraisal. Geophys. J. Int. 134 (1), 291-311. https://doi.org/10.1046/j.1365 246x.1998.00560.x.

Jaupart, C., Labrosse, S., Lucazeau, F., Mareschal, J.-C., 2015. 7.06 - Temperatures, heat, and energy in the mantle of the earth. In: Schubert, G. (Ed.), Treatise on Geophysics (Second Edition), second edition. Elsevier, Oxford, pp. 223-270. http://www.sci encedirect.com/science/article/pii/B9780444538024001263.

Karato, S.-I., 2011. Water distribution across the mantle transition zone and its implications for global material circulation. Earth Planet. Sci. Lett. 301, 413-423.

Katsura, T., Yamada, H., Nishikawa, O., Song, M., Kubo, A., Shinmei, T., Yokoshi, S., Aizawa, Y., Yoshino, T., Walter, M.J., Ito, E., Funakoshi, K.-I., 2004. Olivinewadsleyite transition in the system ( $\mathrm{Mg}, \mathrm{Fe})_{2} \mathrm{SiO}_{4}$. J. Geophys. Res. Solid Earth 109 (B2). https://doi.org/10.1029/2003JB002438.

Katsura, T., Yokoshi, S., Kawabe, K., Shatskiy, A., Okube, M., Fukui, H., Ito, E., Nozawa, A., Funakoshi, K.-I., 2007. Pressure dependence of electrical conductivity of $(\mathrm{Mg}, \mathrm{Fe}) \mathrm{SiO}_{3}$ ilmenite. Phys. Chem. Miner. 34, 249-255.

Khan, A., 2016. On Earth's mantle constitution and structure from joint analysis of geophysical and laboratory-based data: an example. Surv. Geophys. 37, 149-189.

Khan, A., Connolly, J.A.D., Olsen, N., Oct 2006. Constraining the composition and thermal state of the mantle beneath Europe from inversion of long-period electromagnetic sounding data. J. Geophys. Res. Solid Earth 111 (B10), B10102.

Khan, A., Connolly, J.A.D., Taylor, S.R., 2008. Inversion of seismic and geodetic data for the major element chemistry and temperature of the earth's mantle. J. Geophys. Res. Solid Earth 113 (B9). https://doi.org/10.1029/2007JB005239.
Kuvshinov, A., Olsen, N., 2006. A global model of mantle conductivity derived from 5 years of champ, rsted, and sac-c magnetic data. Geophys. Res. Lett. 33 (18) https:// doi.org/10.1029/2006GL027083.

Lahiri, B., Price, A., 1939. Electromagnetic induction in non-uniform conductors, and the determination of the conductivity of the earth from terrestrial magnetic variations. Philos. Trans. R. Soc. Lond. A: Math. Phys. Eng. Sci. 237 (784), 509-540. http://rsta. royalsocietypublishing.org/content/237/784/509.

Landauer, R., 1952. The electrical resistance of binary metallic mixtures. J. Appl. Phys. 23, 779-784.

Le Mouël, J., 1976. L'induction dans le globe. In: Jean, Coulomb, Jobert, Georges (Eds.), Traité de Géophysique Interne, tome 2. Masson, Ch. 29, pp. 129-159.

Marton, F.C., Cohen, R.E., 2002. Constraints on lower mantle composition from molecular dynamics simulations of mgsio3 perovskite. Phys. Earth Planet. Inter. 134 (3), 239-252. http://www.sciencedirect.com/science/article/pii/S003192010200 1899.

Matas, J., Bass, J., Ricard, Y., Mattern, E., Bukowinski, M.S.T., Aug 2007. On the bulk composition of the lower mantle: predictions and limitations from generalized inversion of radial seismic profiles. Geophys. J. Int. 170 (2), 764-780.

Mattern, E., Matas, J., Ricard, Y., Bass, J., Mar 2005. Lower mantle composition and temperature from mineral physics and thermodynamic modelling. Geophys. J. Int. 160 (3), 973-990.

McDonald, K.L., Mar. 1957. Penetration of the geomagnetic secular field through a mantle with variable conductivity. J. Geophys. Res. 62, 117-141.

Munch, F.D., Grayver, A.V., Kuvshinov, A., Khan, A., 2018. Stochastic inversion of geomagnetic observatory data including rigorous treatment of the ocean induction effect with implications for transition zone water content and thermal structure. J. Geophys. Res. Solid Earth 123 (1), 31-51. https://doi.org/10.1002/ 2017JB014691.

Munch, F.D., Grayver, A.V., Guzavina, M., Kuvshinov, A.V., Khan, A., 2020. Joint inversion of daily and long-period geomagnetic transfer functions reveals lateral variations in mantle water content. Geophys. Res. Lett. 47 (10), e87222.

Murakami, M., Ohishi, Y., Hirao, N., Hirose, K., 2012. A perovskitic lower mantle inferred from high-pressure, high-temperature sound velocity data. Nature 485 https://doi.org/10.1038/nature11004.

Novella, D., Frost, D.J., Hauri, E.H., Bureau, H., Raepsaet, C., Roberge, M., 2014. The distribution of $\mathrm{HO}$ between silicate melt and nominally anhydrous peridotite and the onset of hydrous melting in the deep upper mantle. Earth Planet. Sci. Lett. 400, 1-13.

Olsen, N., 1999a. Induction studies with satellite data. Surv. Geophys. 20, 309-340.

Olsen, N., 1999b. Long-period (30 days-1 year) electromagnetic sounding and the electrical conductivity of the lower mantle beneath Europe. Geophys. J. Int. 138, 179-187.

Püthe, C., Kuvshinov, A., 2013. Determination of the 1-D distribution of electrical conductivity in Earth's mantle from Swarm satellite data. Earth Planets Space 65, 1233-1237.

Püthe, C., Kuvshinov, A., Khan, A., Olsen, N., 2015. A new model of Earth's radial conductivity structure derived from over $10 \mathrm{yr}$ of satellite and observatory magnetic data. Geophys. J. Int. 203 (3), 1864-1872.

Sabaka, T.J., Tøffner-Clausen, L., Olsen, N., Finlay, C.C., 2018. A comprehensive model of Earth's magnetic field determined from 4 years of Swarm satellite observations. Earth Planets Space 70 (1), 130.

Semenov, V.Y., Jozwiak, W., 1999. Model of the geoelectrical structure of the mid- and lower mantle in the Europe-Asia region. Geophys. J. Int. 138 (2), 549-552.

Srivastava, S.P., Nov. 1966. Theory of the Magnetotelluric method for a spherical conductor. Geophys. J. 11, 373-387.

Stacey, F.D., Davis, P.M., 2008. Physics of the Earth, 4th ed. Cambridge University Press, Cambridge, New York, Melbourne. xiii 532 pp.

Thébault, E., 2006. Global lithospheric magnetic field modelling by successive regional analysis. Earth Planets Space 58, 485-495.

Thébault, E., Vigneron, P., Langlais, B., Hulot, G., 2016. A Swarm lithospheric magnetic field model to SH degree 80. Earth Planets Space 68 (1), 126.

Tøffner-Clausen, L., Nielsen, J.B., 2018. Swarm Level 1b Product Definition, SW-RS-DSCSY-0007, Issue 5.22. https://earth.esa.int/documents/10174/1514862/Swarm_L1b Product Definition.

Vacher, P., Mocquet, A., Sotin, C., Apr. 1998. Computation of seismic profiles from mineral physics: the importance of the non-olivine components for explaining the $660 \mathrm{~km}$ depth discontinuity. Phys. Earth Planet. Inter. 106, 277-300.

Velímský, J., 2010. Electrical conductivity in the lower mantle: constraints from CHAMP satellite data by time-domain EM induction modelling. Phys. Earth Planet. Inter. 180, 111-117.

Verhoeven, O., Mocquet, A., Vacher, P., Rivoldini, A., Menvielle, M., Arrial, P.-A., Choblet, G., Tarits, P., Dehant, V., Van Hoolst, T., 2009. Constraints on thermal state and composition of the earth's lower mantle from electromagnetic impedances and seismic data. J. Geophys. Res. Solid Earth 114 (B3). https://doi.org/10.1029/ 2008JB005678.

Wolf, A.S., Jackson, J.M., Dera, P., Prakapenka, V.B., 2015. The thermal equation of state of $(\mathrm{Mg}, \mathrm{Fe}) \mathrm{SiO}_{3}$ bridgmanite (perovskite) and implications for lower mantle structures. J. Geophys. Res. Solid Earth 120 (11). https://doi.org/10.1002/ 2015JB012108.

$\mathrm{Wu}, \mathrm{Z}$., 2016. Velocity structure and composition of the lower mantle with spin crossover in ferropericlase. J. Geophys. Res. Solid Earth 121 (4), 2304-2314. https://doi.org/ 10.1002/2015JB012667.

Xu, W., Lithgow-Bertelloni, C., Stixrude, L., Ritsema, J., 2008. The effect of bulk composition and temperature on mantle seismic structure. Earth Planet. Sci. Lett. 275 (1), 70-79. http://www.sciencedirect.com/science/article/pii/S0012821 X08005281. 
Yoshino, T., 2010. Laboratory electrical conductivity measurement of mantle minerals. Surv. Geophys. 31, 163-206.

Yoshino, T., Katsura, T., 2012a. Erratum to: re-evaluation of electrical conductivity of anhydrous and hydrous wadsleyite. Earth Planet. Sci. Lett. 357-358, 422. http:// www.sciencedirect.com/science/article/pii/S0012821X1200581X.

Yoshino, T., Katsura, T., 2012b, Re-evaluation of electrical conductivity of anhydrous and hydrous wadsleyite. Earth Planet. Sci. Lett. 337338, 56-67.

Yoshino, T., Manthilake, G., Matsuzaki, T., Katsura, T., 2008a. Dry mantle transition zone inferred from the conductivity of wadsleyite and ringwoodite. Nature 451 326-329.

Yoshino, T., Nishi, M., Matsuzaki, T., Yamazaki, D., Katsura, T., 2008b. Electrical conductivity of majorite garnet and its implications for electrical structure in the mantle transition zone. Phys. Earth Planet. Inter. 170, 193-200.

Yoshino, T., Matsuzaki, T., Shatskiy, A., Katsura, T., 2009. The effect of water on the electrical conductivity of olivine aggregates and its implications for the electrical structure of the upper mantle. Earth Planet. Sci. Lett. 288, 291-300.

Yoshino, T., Ito, E., Katsura, T., Yamazaki, D., Shan, S., Guo, X., Nishi, M., Higo, Y., Funakoshi, K.-I., 2011. Effect of iron content on electrical conductivity of ferropericlase with implications for the spin transition pressure. J. Geophys. Res. Solid Earth 116, 4202
Yoshino, T., Shimojuku, A., Shan, S., Xinzhuan, G., Guo, X., Yamazaki, D., Ito, E., Higo, Y., Funakoshi, K.-I., 2012. Effect of temperature, pressure and iron content on the electrical conductivity of olivine and its high-pressure polymorphs. J. Geophys. Res. Solid Earth 117.

Yoshino, T., Kamada, S., Zhao, C., Ohtani, E., Hirao, N., 2016. Electrical conductivity model of Al-bearing bridgmanite with implications for the electrical structure of the Earth's lower mantle. Earth Planet. Sci. Lett. 434, 208-219.

Zhang, B., Yoshino, T., 2016. Effect of temperature, pressure and iron content on the electrical conductivity of orthopyroxene. Contrib. Mineral. Petrol. 171, 102.

Zhang, B., Yoshino, T., Wu, X., Matsuzaki, T., Shan, S., Katsura, T., 2012. Electrical conductivity of enstatite as a function of water content: implications for the electrical structure in the upper mantle. Earth Planet. Sci. Lett. 357, 11-20.

Zhang, Z., Stixrude, L., Brodholt, J., 2013. Elastic properties of mgsio3-perovskite under lower mantle conditions and the composition of the deep earth. Earth Planet. Sci. Lett. 359, 1-12. http://www.sciencedirect.com/science/article/pii/S0012821X1 3004093.

Zhao, C., Yoshino, T., 2016. Electrical conductivity of mantle clinopyroxene as a function of water content and its implication on electrical structure of uppermost mantle. Earth Planet. Sci. Lett. 447, 1-9. 